\title{
Trial Indication
}

National Cancer Institute

\section{Source}

National Cancer Institute. Trial Indication. NCI Thesaurus. Code C112038.

The disease under study which serves as the basis for initiation of a study treatment in a clinical trial. 